\title{
Canadian consensus algorithm for erectile rehabilitation following prostate cancer treatment
}

Dean S. Elterman ${ }^{1}$; Anika R. Petrella ${ }^{1}$; Lauren M. Walker ${ }^{2}$; Brandon Van Asseldonk ${ }^{1}$; Leah Jamnicky $^{1}$; Gerald B. Brock ${ }^{3}$; Stacy Elliott ${ }^{2}$; Antonio Finelli ${ }^{1}$; Jerzy B. Gajewski ${ }^{4}$; Keith A. Jarvi $^{5}$; John Robinson ${ }^{6}$; Janet Ellis ${ }^{7}$; Shaun Shepherd ${ }^{1}$; Hossein Saadat ${ }^{1}$; Andrew Matthew ${ }^{1}$ ${ }^{1}$ Division of Urology, University Health Network, Toronto, ON, Canada; ${ }^{2}$ Department of Psychiatry, University of British Columbia, Vancouver, BC, Canada; ${ }^{3}$ Department of Surgery, St. Joseph’s Hospital, London, ON, Canada; ${ }^{4}$ Department of Urology, Dalhousie University, Halifax, NS, Canada; ${ }^{5}$ Murray Koffler Urologic Wellness Centre, Mount Sinai Hospital, Toronto, ON, Canada; ${ }^{6}$ Clinical Psychology Department, University of Calgary, Calgary, AB, Canada; ${ }^{7}$ Department of Psychology, Sunnybrook Health Sciences Centre, Toronto, ON, Canada

Funding: The consensus meeting was funded by a Prostate Cancer Canada Movember grant.

Cite as: Can Urol Assoc J 2018 December 3; Epub ahead of print. http://dx.doi.org/10.5489/cuaj.5653

Published online December 3, 2018

$* * *$

\section{Abstract}

Introduction: The present descriptive analysis carried out by a pan-Canadian panel of expert healthcare practitioners (HCPs) summarizes best practices for erectile rehabilitation following prostate cancer (PCa) treatment. This algorithm was designed to support an online sexual health and rehabilitation e-clinic (SHARe-Clinic), which provides biomedical guidance and supportive care to Canadian men recovering from PCa treatment. The implications of the algorithm may be used inform clinical practice in community settings.

Methods: Men's sexual health experts convened for the TrueNTH Sexual Health and Rehabilitation Initiative Consensus Meeting to address concerns regarding erectile dysfunction (ED) therapy and management following treatment for PCa. The meeting brought together experts from across Canada for a discussion of current practices, latest evidence-based literature review, and patient interviews.

Results: An algorithm for ED treatment following PCa treatment is presented that accounts for treatment received (surgery or radiation), degree of nerve-sparing, and level of pro-erectile treatment invasiveness based on patient and partner values. This algorithm provides an approach from both a biomedical and psychosocial focus that is tailored to the patient/partner presentation. 
Regular sexual activity is recommended, and the importance of partner involvement in the treatment decision-making process is highlighted, including the management of partner sexual concerns.

Conclusions: The algorithm proposed by expert consensus considers important factors like the type of PCa treatment, the timeline of erectile recovery, and patient values, with the goal of becoming a nationwide standard for erectile rehabilitation following PCa treatment.

\section{Introduction}

Prostate cancer (PCa) is the second most frequent cancer found in men, accounting for $21 \%$ of the estimated new annual cases. ${ }^{1,2}$ A number of treatment options are available to patients with PCa, including active surveillance (AS), radiotherapy (RT), and radical prostatectomy (RP). Treatment options are chosen based on a number of factors, such as clinical stage, patient's age, and the presence of co-morbid diseases in the patient. ${ }^{3,4}$

PCa treatments, regardless of modality, increase the likelihood of erectile dysfunction (ED). ${ }^{5}$ Rates for ED lasting 2 years or more following RP range from $66-75 \% .{ }^{5,6}$ Similar results are reported in men following RT at 3 years (37-81\%). ${ }^{7}$ ED rates have been found to be 10 to 15 fold higher in men with PCa than their similarly aged peers. ${ }^{8}$ ED is a significant threat to the quality of life of men diagnosed with PCa, as $60 \%$ of affected men experience severe distress from ED. ${ }^{9-11}$ The loss of sexual activity and resultant challenge to masculinity have been shown to negatively affect quality of life. ${ }^{12}$

Currently, there remains a gap in the systematic and comprehensive care of sexual dysfunction after PCa treatment. This presents a significant barrier to continuity of care for PCa survivors across Canada. The TrueNTH SHARe Clinic was developed to provide sexual health support to men located across Canada. The present manuscript incorporates research evidence, patient perspectives and clinical expertise from experts in the field. To address the lack of consistency in care of sexual dysfunction after PCa treatment a meeting was held. The TrueNTH Sexual Health and Rehabilitation Initiative Consensus Meeting was held with the purpose of developing an ED therapy algorithm following PCa treatment. The algorithm would be disseminated and used in the TrueNTH SHARe Clinic. The present manuscript describes the development of an ED therapy algorithm that uniquely accounts for patient and partner values and goals for erectile recovery, type of PCa treatment, time since treatment, nerve-sparing status, and also includes thematic recommendations for psychosocial support

\section{Methods}

A pan-Canadian panel of men's sexual health experts convened for the TrueNTH Sexual Health and Rehabilitation Initiative Meeting to develop a consensus on treating ED in patients treated for localized PCa. The consensus panel meeting was held on October 31, 2016 in Toronto. A limited peer esteem snowballing technique (PEST) was used to identify expert opinion panellists 
based on research or clinical expertise in sexual dysfunction post-PCa treatment. ${ }^{13}$ A 17 -member expert opinion panel provided commentary on variation in ED treatment approaches through various programs and services across Canada. The group represented a wide range of backgrounds including nursing, urology, urologic oncology, radiation oncology, psychology, psychiatry, as well as patient advocates.

The meeting involved several key decision-making components. Before the consensus meeting, all panelists reviewed the evidence-based medical literature on ED, particularly concerning physiology, pathophysiology, diagnosis, and treatment of ED following PCa treatment. The meeting began with a discussion of various cancer-related sexual health rehabilitation programs that exist across the country. Special attention was paid to patients' concerns about the current practice of ED therapy and management following PCa treatment, specifically the advantages and disadvantages of existing practices. Subsequently, the latest clinical guidelines on sexual rehabilitation after PCa treatment were reviewed and summarized. ${ }^{14-16}$

Patients' perspectives and feedback regarding gaps in current practice and desired practice were incorporated into the development of the TrueNTH SHARe Clinic algorithm. Possibilities for content and structure were outlined and discussed. Proposed strategies for the uptake of the algorithm to the medical community were also outlined.

\section{Results}

The TrueNTH Sexual Health and Rehabilitation Initiative Consensus Meeting established that a tailored, comprehensive ED therapy algorithm for patients (and their partners) after localized PCa treatment should recognize the following:

1) real-life results are often more modest than reported in the literature;

2) patients are overly optimistic about the likelihood that they will be in the minority of patients who do not experience ED and about the ease with which they will adapt to use of pro-erectile therapies; ${ }^{17,18}$

3) poorly managed patient expectations can be demotivating in sustaining use of pro-erectile therapies;

4) while the best time to introduce erectile rehabilitation remains unclear, pre-PCa treatment psychoeducation on sexual dysfunction and available ED therapies is a necessity; ${ }^{19-22}$

5) post-PCa treatment ED recovery typically occurs over a minimum of two (or more) years; ${ }^{23}$

6) desired pace of return of ED function and willingness to engage in invasive treatment varies across patients and partners; ${ }^{24,25}$

7) exclusive focus on achieving erections via any means, may overlook the values or goals of patients and their partners;

8) the uptake and adherence to pro-erectile therapies is generally poor; ${ }^{26-28}$

9) detailed education on the systematic use of pro-erectile therapies is often lacking in postPCa sexual health care; ${ }^{19}$ 
10) inclusion of the partner in the recovery process is optimal; ${ }^{24,29-31}$

11) the process of ED therapy re-challenging over the recovery period is necessary to achieve optimal erectile functioning and to manage perceived treatment failure; ${ }^{32}$

12) maintaining regular sexual activity (penetrative or non-penetrative) during the course of erectile recovery is advantageous for individuals and couple's well-being. ${ }^{33,34}$

\section{Algorithm}

The algorithm for managing ED is illustrated in Table 1. The algorithm focuses on therapeutic strategies to erectile recovery, with psychosocial considerations at each stage of treatment. The focus of the algorithm is split based on patients' values or goals for erectile recovery. Further considerations are offered based on the cancer treatment (radiation or surgery), nerve-sparing status, preference for less invasive vs. more aggressive treatment approach, and inclination for a pharmaceutical vs. mechanical approach to pro-erectile therapy.

\section{Section 1: Algorithm process}

Patients will choose a management pathway (Table 1) based on the type of PCa treatment received (surgery or radiation), followed by the patients desired level of invasiveness (low or high), and the nerve sparing status (bilateral nerve sparing; BNS, unilateral nerve sparing; UNS, and non-nerve sparing; NNS), and lastly if they prefer a pharmaceutical vs. mechanical approach to pro-erectile therapy. Thus, vacuum erection devices (VED) are available in each quadrant for a non-biomedical approach. The inflatable penile prosthesis is available for patients who are refractory to both biomedical and non-biomedical approaches, however as this strategy is often reserved later in the treatment trajectory (beyond 2 years) to allow sufficient time for natural recovery and sufficient retrial with first-line treatments, it is not presented in the algorithm. ${ }^{35}$ Patient's preferences are also taken into account in terms of tolerance of degree of treatment invasiveness, and the patients' goals for erectile recovery (articulated further in section 2 below). In addition to the specific recommendations for pro-erectile therapy, patients are recommended to maintain regular sexual activity (at least weekly) whether penetrative or non-penetrative, and/ or masturbation. Clinicians may also consider combination therapies if necessary, depending on the patient's desire to challenge ED over time. ${ }^{36,37}$

Section 2: Patient goals for erectile recovery and psychosocial considerations As a supplemental document to the algorithm, Table 2 outlines patients' values and goals for erectile rehabilitation and should be used as a resource to guide treatment planning. The panel agreed that there were essentially two pathways that the patient might choose. The primary goals of "long-term penile health" and (i.e. optimising changes for natural recovery of erections with a relatively non-invasive approach) vs. "short-term erectile function" were identified in the algorithm. Clinicians are encouraged to assess the patient's goals for outcomes as this may change with time. Furthermore, partners may also wish to provide input into these goals. 


\section{Section 3: Benchmarking and normalization}

In addition to the algorithm based on patient treatment and preference for ED rehabilitation (pharmaceutical vs. mechanical), the panel noted the importance of providing patients with a point of reference for their progress in terms of expected timeline of erectile function recovery. This attempt at typical response benchmarking is intended to help patients manage their expectations and normalize their recovery process. The panel determined that sufficient empirical evidence for typical response benchmarking was only available for the post-radical patient population (see Table 3). More research is needed to determine the timeline for patients treated with radiation therapy. ${ }^{38}$

\section{Discussion}

Developing a treatment plan for ED after PCa involves balancing a number of factors including different trajectories for radiation vs. surgical treatment, nerve-sparing status, and the degree of invasiveness of various pro-erectile therapies, along with determining patient and partner's goals for erectile recovery. ${ }^{20-23}$ Other patient related factors must all be considered in ensuring that proerectile therapies are optimally successful including: patient expectations of pro-erectile therapy and timeline of recovery, the role of the partner in erectile recovery, and the patients' sexual beliefs, masculine values, possible grief in response to sexual losses, and potential performance anxiety. ${ }^{39-41}$

Sub-algorithms were proposed for each group of patients (e.g. those treated with radiation vs. surgery), as the panel recognized advantages to more accurately capture between-group differences such as different trajectory of impact of PCa treatment on erectile function. Consensus on structures of the sub-algorithms was achieved; the structure would include consideration for timeline benchmarks, long-term penile health vs. short-term erectile function, as well as additional sexual concerns, all while integrating patient preferences.

Suggested timeline benchmarks for the sub-algorithms were 1-3, 6, 12, 18, and 24 months from baseline, for surgical outcomes only. The suggested benchmarks were based on historical practice adopted in clinical trials and the expected success rates of relevant treatment approaches. However, a significant limitation is the limited empirical evidence due to heterogeneity in treatment timelines and a low risk of external validity in clinical studies. Further discussion is required to establish outcome benchmarks for patients with a delayed response to treatment and also for patients receiving radiation therapy.

The sub-algorithm structure for penile rehabilitation (i.e. long-term care of penile health) was designed to focus on treatment flow with emphasis placed on the patient's desire to engage in strategies that would promote penile health and improve capacity for natural return of erections with time. This sub-algorithm also considers the patients' tolerance of treatment invasiveness. Consistent with treatment guidelines, phosphodiesterase type 5 inhibitors (PDE5i) were identified as first-line treatment for ED post RP with either daily or as-needed dosing. ${ }^{35}$ Daily PDE5i dosing has demonstrated to be an effective alternative to as-needed dosing in patients in patients who had an incomplete response to therapy with maximum-dose as-required 
PDE5i. ${ }^{42}$ If patient response to PDE5i is poor at 3 months, the introduction of intracavernous injection (ICI) treatment can be introduced as an option, with the possible retrial of PDE5i. Alternatively, treatment with VED can be used in place of ICI or PDE5i at any point in the recovery timeline thus patient treatment preference should be prioritized to guide long-term clinical management.

In response to direct feedback from patients and clinicians on the panel, patient preference for expedient recovery of erections was identified as an alternative goal to long-term penile health. In this scenario, the short-term erectile function component of the algorithm should be followed (right column). The first increment of the treatment timeline should be 1-3 months. Patients motivated to achieve an erection immediately, should initiate ICI therapy as first-line treatment. Otherwise, if treating with PDE5i, a higher dose is recommended with the possibility of combined treatment with ICI and/or the VED ${ }^{36}$

The following considerations were identified for inclusion in the content of the subalgorithms: climacturia, dysorgasmia, alterations to penile anatomy, and reduced sexual desire. Other psychosexual factors that interact with patient preferences were considered for inclusion such as the importance of sexual activity and intimacy, expectations for recovery with proerectile therapy, performance anxiety, and the recognition of the impact of loss and grief. Important highlights included interventions to communicate the importance of persistence to therapy, are required to ensure patients can realize the full benefits of clinical therapy. Psychosocial interventions are required to redefine patient sex life, integrating the sexual partner(s) when possible, and focusing on building on therapeutic gains.

Patients should be counselled about the likelihood of natural recovery of erections and timelines for recovery, including the significant role of the patients' baseline erectile function prior to PCa treatment. In fact, baseline erectile function may have even more influence on erectile recovery than use of pro-erectile therapies. ${ }^{43}$ Age is also a major predictor, with younger men showing better natural erectile recovery. ${ }^{23,44}$ The percent probability of erectile recovery by 24 months, for men who have full erections at baseline is $63 \% \leq 60$ years vs. $37 \%$ in men $\geq 65$ years. In contrast, in men with recently diminished erectile function at baseline, the percent probability is lower at $48 \% \leq 60$ years vs. $26 \%$ in men $\geq 65$ years, and even worse for men who had partial erectile function at baseline, $35 \% \leq 60$ years vs. $18 \%$ in men $\geq 65$ years. Rates in all categories increase slightly out to 36 months. $^{23}$

Additional insights from the literature should be considered when counselling patients about erectile recovery, in order to promote adherence to, and acceptance of the use of proerectile therapies. For example, in the general population, sustained use of PDE5i is better when prescribed with the knowledge and involvement of the patients' partner. ${ }^{45}$ Given the overly optimistic mindset of patients about the probability of experiencing ED and the ease of treatments for ED, patients need adequate preparation before starting pro-erectile therapy. The algorithm was designed with the explicit purpose of being embedded in sexual health programming for PCa patients. ${ }^{18}$ 
The most common reason for discontinuation of PDE5i is lack of treatment efficacy (e.g. hardness of erection), ${ }^{27}$ therefore, in a context when the need to re-challenge is the norm, patients need to be forewarned that PDE5i may not work for all patients immediately, and that likelihood of effectiveness increases the further out the patient is from surgery. ${ }^{16,46}$ In the context of radiation therapy, the opposite effect is observed. Patients often do not understand that tactile stimulation is necessary to prompt an erectile response even with the use of PDE5i and that spontaneous erections are unlikely. ${ }^{47}$ Furthermore, patients should be informed that none of the pro-erectile therapies promote sexual desire or interest.

In addition, a variety of psychosocial factors are listed throughout the Table 2. Ideally good erectile rehabilitation should be provided in a bio-psychosocial context. Where this is not

possible, clinicians may wish to read the evidence-based literature for suggestions on enhancing the likelihood of successful sexual recovery.

The long-term goal is to utilize the treatment algorithms in the development of the webbased TrueNTH SHARe-Clinic. The opinion of the panel was that the application of a personalized clinical treatment tool with the TrueNTH SHARe-Clinic will improve treatment for ED in PCa patients by tailoring individualized therapies in a clinical environment that promotes patients' participation in decision making. The web-based clinic features tailored content including: personalized sexual health coaching, a multimodal virtual library, and symptom monitoring with feedback mechanisms. Thus, the TrueNTH SHARe Clinic uniquely combines web-based sexual health counselling, with an ED therapy algorithm designed to provide patients and their partners with accessible, personalized, post-PCa long-term sexual health care.

\section{Conclusion}

Because of the significantly high rate of ED after PCa treatment, it is critical to establish practices guidelines for the management of ED in this patient population. There exist a number of clinical guidelines to inform first-line through fourth or fifth line therapies, however, to date, none of these guidelines attempt to directly incorporate patient values into the treatment decision making process. Instead they seem to focus on a linear progression of pro-erectile aids from least invasive to most invasive. However, ideal clinical management must be tailored to patient (and partner) preferences including specific goals for erectile recovery. In addition, considerations from the diverse representation on the multi-disciplinary panel highlighted the inclusion of patient experiences directly identified by patient advocates, as well as psychosocial recommendations to enhance patient and partner efficacy, acceptance, and compliance with proerectile aids. Furthermore, sensitivity to the discrepancies in trajectory of ED development after radiation treatment vs. surgery need to be accommodated when making recommendations in order to maximize applicability. Further work is required to define subsequent clinical management benchmarks, particularly in the context of radiation treatment. The development of an algorithm that incorporates these many different facets, should prove a novel and useful tool for clinicians wishing to support patient's erectile recovery after PCa treatment. 


\section{References}

1. Ferlay J, Soerjomataram I, Dikshit R, et al. Cancer incidence and mortality worldwide: Sources, methods and major patterns in globocan 2012. Int J Cancer 2015;136:E359-86. 2014/09/16.

2. Canadian Cancer Society's Steering Committee for Canadian Cancer Statistics. Canadian cancer statistics 2017. Toronto, ON: Canadian Cancer Society;2017.

3. Zumsteg ZS, Spratt DE, Pei I, et al. A new risk classification system for therapeutic decision making with intermediate-risk prostate cancer patients undergoing doseescalated external-beam radiation therapy. Eur Urol 2013;64:895-902. 2013/04/02.

4. Epstein JI, Zelefsky MJ, Sjoberg DD, et al. A contemporary prostate cancer grading system: A validated alternative to the gleason score. Eur Urol 2016;69:428-35. 2015/07/15.

5. Robinson JW, Moritz S, Fung T. Meta-analysis of rates of erectile function after treatment of localized prostate carcinoma. Int J Radiat Oncol Biol Phys 2002;54:1063-8. 2002/11/07.

6. Haglind E, Carlsson S, Stranne J, et al. Urinary incontinence and erectile dysfunction after robotic versus open radical prostatectomy: A prospective, controlled, nonrandomised trial. Eur Urol 2015;68:216-25. 2015/03/17.

7. Akbal C, Tinay I, Simsek F, et al. Erectile dysfunction following radiotherapy and brachytherapy for prostate cancer: Pathophysiology, prevention and treatment. Int Urol Nephrol 2008;40:355-63. 2007/10/26.

8. Bacon CG, Mittleman MA, Kawachi I, et al. Sexual function in men older than 50 years of age: Results from the health professionals follow-up study. Ann Intern Med 2003;139:161-8. 2003/08/06.

9. Nelson CJ, Mulhall JP, Roth AJ. The association between erectile dysfunction and depressive symptoms in men treated for prostate cancer. J Sex Med 2011;8:560-6. 2010/12/16.

10. Cooperberg MR, Koppie TM, Lubeck DP, et al. How potent is potent? Evaluation of sexual function and bother in men who report potency after treatment for prostate cancer: Data from capsure. Urology 2003;61:190-6. 2003/02/01.

11. Penson DF, Latini DM, Lubeck DP, et al. Is quality of life different for men with erectile dysfunction and prostate cancer compared to men with erectile dysfunction due to other causes? Results from the exceed data base. J Urol 2003;169:1458-61. 2003/03/12.

12. Bourke L, Boorjian SA, Briganti A, et al. Survivorship and improving quality of life in men with prostate cancer. Eur Urol 2015;68:374-83. 2015/05/06.

13. Christopoulos D. Peer esteem snowballing: A methodology for expert surveys. Paper presented at: Eurostat conference for new techniques and technologies for statistics2009.

14. Chung E, Brock GB. Emerging and novel therapeutic approaches in the treatment of male erectile dysfunction. Curr Urol Rep 2011;12:432-43. 2011/09/17.

15. Salonia A, Burnett AL, Graefen M, et al. Prevention and management of postprostatectomy sexual dysfunctions part 2: Recovery and preservation of erectile function, sexual desire, and orgasmic function. Eur Urol 2012;62:273-86. 2012/05/12.

16. Kirby MG, White ID, Butcher J, et al. Development of uk recommendations on treatment for post-surgical erectile dysfunction. Int J Clin Pract 2014;68:590-608. 2013/11/06. 
17. Wittmann D, He C, Coelho M, et al. Patient preoperative expectations of urinary, bowel, hormonal and sexual functioning do not match actual outcomes 1 year after radical prostatectomy. J Urol 2011;186:494-9. 2011/06/18.

18. Bronner G, Shefi S, Raviv G. Sexual dysfunction after radical prostatectomy: Treatment failure or treatment delay? J Sex Marital Ther 2010;36:421-9. 2010/10/07.

19. Boberg EW, Gustafson DH, Hawkins RP, et al. Assessing the unmet information, support and care delivery needs of men with prostate cancer. Patient Educ Couns 2003;49:23342. 2003/03/19.

20. Vickers AJ, Kent M, Mulhall J, et al. Counseling the post-radical prostatectomy patients about functional recovery: High predictiveness of current status. Urology 2014;84:15863. 2014/05/16.

21. Wittmann D, Montie JE, Hamstra DA, et al. Counseling patients about sexual health when considering post-prostatectomy radiation treatment. Int J Impot Res 2009;21:27584. 2009/07/18.

22. Forbat L, White I, Marshall-Lucette S, et al. Discussing the sexual consequences of treatment in radiotherapy and urology consultations with couples affected by prostate cancer. BJU Int 2012;109:98-103. 2011/06/03.

23. Rabbani F, Stapleton AM, Kattan MW, et al. Factors predicting recovery of erections after radical prostatectomy. J Urol 2000;164:1929-34. 2000/11/04.

24. Wittmann D, Carolan M, Given B, et al. Exploring the role of the partner in couples' sexual recovery after surgery for prostate cancer. Support Care Cancer 2014;22:2509-15. 2014/04/15.

25. Davison BJ, Keyes M, Elliott S, et al. Preferences for sexual information resources in patients treated for early-stage prostate cancer with either radical prostatectomy or brachytherapy. BJU Int 2004;93:965-9. 2004/05/15.

26. Lee DJ, Cheetham P, Badani KK. Penile rehabilitation protocol after robot-assisted radical prostatectomy: Assessment of compliance with phosphodiesterase type 5 inhibitor therapy and effect on early potency. BJU Int 2010;105:382-8. 2009/09/15.

27. Buvat J, Buttner H, Hatzimouratidis K, et al. Adherence to initial pde-5 inhibitor treatment: Randomized open-label study comparing tadalafil once a day, tadalafil on demand, and sildenafil on demand in patients with erectile dysfunction. J Sex Med 2013;10:1592-602. 2013/04/05.

28. Matthew AG, Goldman A, Trachtenberg J, et al. Sexual dysfunction after radical prostatectomy: Prevalence, treatments, restricted use of treatments and distress. J Urol 2005;174:2105-10. 2005/11/11.

29. Davison BJ, Matthew A, Elliott S, et al. Assessing couples' preferences for postoperative sexual rehabilitation before radical prostatectomy. BJU international 2012;110:1529-35.

30. Fisher WA, Eardley I, Mccabe M, et al. Erectile dysfunction (ed) is a shared sexual concern of couples ii: Association of female partner characteristics with male partner ed treatment seeking and phosphodiesterase type 5 inhibitor utilization. J Sex Med 2009;6:3111-24. 2009/08/14.

31. Dunn ME. Restoration of couple's intimacy and relationship vital to reestablishing erectile function. J Am Osteopath Assoc 2004;104:S6-10. 2004/04/16.

32. Jiann BP, Yu CC, Su CC, et al. Rechallenge prior sildenafil nonresponders. Int J Impot Res 2004;16:64-8. 2004/02/14. 
33. Wittmann D, Carolan M, Given B, et al. What couples say about their recovery of sexual intimacy after prostatectomy: Toward the development of a conceptual model of couples' sexual recovery after surgery for prostate cancer. The journal of sexual medicine 2015;12:494-504.

34. Walker LM, Wassersug RJ, Robinson JW. Psychosocial perspectives on sexual recovery after prostate cancer treatment. Nature Reviews Urology 2015;12:167.

35. Bella AJ, Lee JC, Carrier S, et al. 2015 CUA practice guidelines for erectile dysfunction. Canadian Urological Association Journal 2015;9:23.

36. Kimura M, Caso JR, Banez LL, et al. Predicting participation in and successful outcome of a penile rehabilitation programme using a phosphodiesterase type 5 inhibitor with a vacuum erection device after radical prostatectomy. BJU Int 2012;110:E931-8. 2012/04/24.

37. Defade BP, Carson CC, 3rd, Kennelly MJ. Postprostatectomy erectile dysfunction: The role of penile rehabilitation. Rev Urol 2011;13:6-13. 2011/08/10.

38. Wiegner EA, King CR. Sexual function after stereotactic body radiotherapy for prostate cancer: Results of a prospective clinical trial. Int J Radiat Oncol Biol Phys 2010;78:4428. 2010/02/09.

39. Zaider T, Manne S, Nelson C, et al. Loss of masculine identity, marital affection, and sexual bother in men with localized prostate cancer. J Sex Med 2012;9:2724-32. 2012/09/20.

40. Gannon K, Guerro-Blanco M, Patel A, et al. Re-constructing masculinity following radical prostatectomy for prostate cancer. Aging Male 2010;13:258-64. 2010/11/12.

41. Wittmann D, Foley S, Balon R. A biopsychosocial approach to sexual recovery after prostate cancer surgery: The role of grief and mourning. J Sex Marital Ther 2011;37:13044. 2011/03/15.

42. Kim E, Seftel A, Goldfischer E, et al. Comparative efficacy of tadalafil once daily in men with erectile dysfunction who demonstrated previous partial responses to as-needed sildenafil, tadalafil, or vardenafil. Curr Med Res Opin 2015;31:379-89. 2014/12/03.

43. Castiglione F, Nini A, Briganti A. Penile rehabilitation with phosphodiesterase type 5 inhibitors after nerve-sparing radical prostatectomy: Are we targeting the right patients? Eur Urol 2014;65:673-4. 2014/01/07.

44. Gallina A, Ferrari M, Suardi N, et al. Erectile function outcome after bilateral nerve sparing radical prostatectomy: Which patients may be left untreated? J Sex Med 2012;9:903-8. 2012/01/14.

45. Carvalheira AA, Pereira NM, Maroco J, et al. Dropout in the treatment of erectile dysfunction with pde5: A study on predictors and a qualitative analysis of reasons for discontinuation. J Sex Med 2012;9:2361-9. 2012/05/24.

46. Montorsi F, Brock G, Stolzenburg JU, et al. Effects of tadalafil treatment on erectile function recovery following bilateral nerve-sparing radical prostatectomy: A randomised placebo-controlled study (reactt). Eur Urol 2014;65:587-96. 2013/10/31.

47. Sadovsky R, Brock GB, Gutkin SW, et al. Toward a new 'epoch': Optimising treatment outcomes with phosphodiesterase type 5 inhibitors for erectile dysfunction. Int J Clin Pract 2009;63:1214-30. 2009/07/25. 
Figures and Tables

Table 1. Pro-erectile therapy algorithm. BNS: bilateral nerve sparing; ICI: intracavernous injection; NNS: non-nerve sparing; PC: prostate cancer; PDE5i: phosphodiesterase type 5 inhibitors; UNS: unilateral nerve sparing; VED: vacuum erection devices.

\section{Pro-erectile Therapy Algorithm}

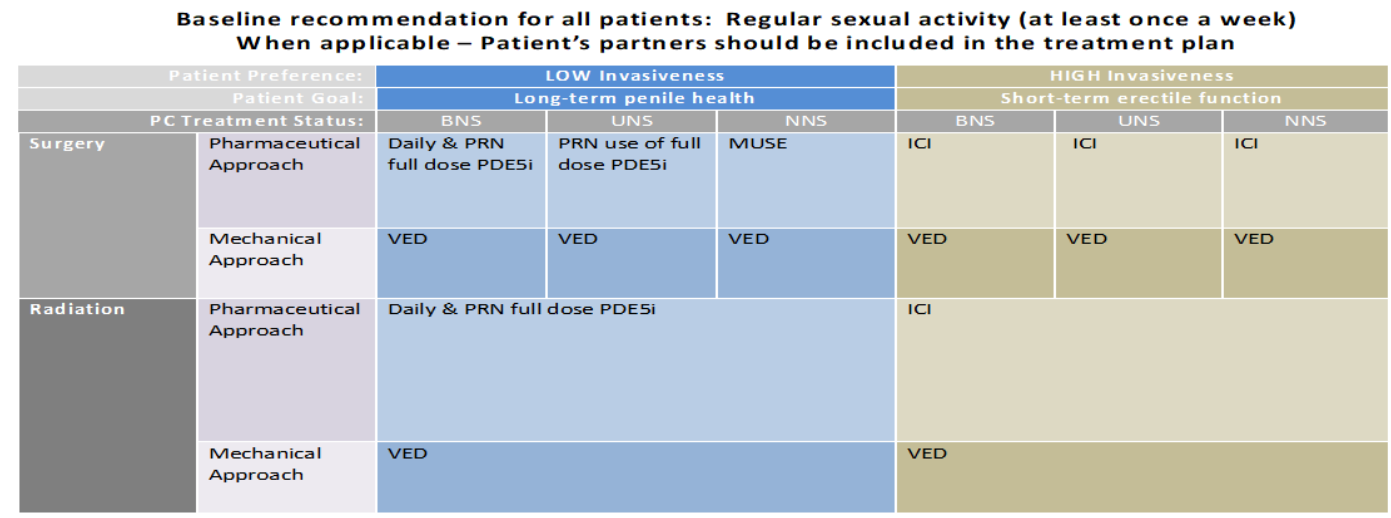


Table 2. Timelines and patient goals for erectile recovery. ICI: intracavernous injection; PDE5i: phosphodiesterase type 5 inhibitors; VED: vacuum erection devices.

\section{- Consider time since treatment and expectation management}

\begin{tabular}{|c|c|c|}
\hline \multirow[b]{2}{*}{ Timeline } & \multicolumn{2}{|c|}{ Patient Goal for Erectile Recovery } \\
\hline & Long-term penile health & Short-term erectile function \\
\hline \multirow[t]{2}{*}{ Prior to treatment } & $\begin{array}{l}\text { Treatment flow post treatment focused on the patient's desire to maintain } \\
\text { penile health over the long term. }\end{array}$ & $\begin{array}{l}\text { Treatment flow post treatment focused on the patient's desire to achieve } \\
\text { functional erections in the short term. }\end{array}$ \\
\hline & $\begin{array}{r}\text { Psychosocial focus: Narmalize use of pro-erectile aids, education on timeline } \\
\text { erectile therapies, exploring patient goals for erectile re }\end{array}$ & $\begin{array}{l}\text { of recovery, manage expectation for erectile recovery and success with use of pro- } \\
\text { overy. "Note: patient goals should be contimuously evaluated }\end{array}$ \\
\hline \multirow[t]{2}{*}{$\begin{array}{l}\text { 6-weeks post } \\
\text { treatment }\end{array}$} & $\begin{array}{l}\text { - POESi first-line; dosage, daily vs. PRAN } \\
\text { - } \quad \text { Include penile stimulation in treatrnent flow }\end{array}$ & $\begin{array}{l}\text { - Include penile stimulation in treatment flow } \\
\text { - If immediate erection is the goal, consider ICI therapy first-line; or possibly } \\
\text { PDCS, full dose if responsive }\end{array}$ \\
\hline & \multicolumn{2}{|c|}{$\begin{array}{l}\text { Asychosocial focus: importance of regular sexual activity (penetrative or non-penetrative), education an timeline of recovery, manage expectation for erectile } \\
\text { recovery and success with use of pro-erectile therapies, encourage couples to maintaining sexual intimacy (penetrative or non-penetrative) }\end{array}$} \\
\hline \multirow[t]{2}{*}{$\begin{array}{l}\text { 10-weeks post } \\
\text { treatment }\end{array}$} & $\begin{array}{l}\text { PDESi first-line; dosage, daily vs. PRN } \\
\text { Include penile stimulation in trestment flow }\end{array}$ & $\begin{array}{l}\text { - Include penile stimulation in treatment flow } \\
\text { - If immediate erection is the goal, consider iCI therapy first-line; or possibly } \\
\text { PDESi full dose if responsive }\end{array}$ \\
\hline & \multicolumn{2}{|c|}{$\begin{array}{l}\text { Psychosocial focus: Assessment and treatment of Partner Concerns, Encouraging adherence to pro-erectile treatment plan, encourage couples to maintaining } \\
\qquad \text { sexual intimacy (penetrative or non-penetrative) }\end{array}$} \\
\hline \multirow{2}{*}{$\begin{array}{l}4 \text { months post } \\
\text { treatment }\end{array}$} & $\begin{array}{l}\text { - For patients who do not respond initially to PDESi's, introduce ICI or } \\
\text { MUSE or VED }\end{array}$ & $\begin{array}{l}\text { - Depending on response to PDEST, cansider continued use of effective } \\
\text { PDESi ar ICl ar MUSE or VED }\end{array}$ \\
\hline & \multicolumn{2}{|c|}{$\begin{array}{l}\text { Psychosotial focus: Recagnition of grief response to sexual losses ar performance anciety, acknowiedge impact on masculinity, encourage couples to } \\
\text { maintaining sexual intimacy (penetrative of non-penetrative) }\end{array}$} \\
\hline \multirow{2}{*}{$\begin{array}{l}6 \text { months post } \\
\text { treatment }\end{array}$} & $\begin{array}{l}\text { For patients who do not respond initially to PDESi's, introduce ICI or } \\
\text { MUSE ar VED }\end{array}$ & $\begin{array}{l}\text { - Depending on response to POEST, cansider continued use of effective } \\
\text { PDESi or ICl ar MUSE ar VED }\end{array}$ \\
\hline & \multicolumn{2}{|c|}{$\begin{array}{l}\text { Psychosocial focus: Re-visit expectations and goals \& explore level of patient bother due to ED; Sexual desire and fantasy, encourage couples to maintaining sexual } \\
\text { intimacy (penetrative or non-penetrative) }\end{array}$} \\
\hline \multirow[t]{2}{*}{$\begin{array}{l}12 \text { months post } \\
\text { treatment }\end{array}$} & $\begin{array}{l}\text { Rechallenge with PDESi as needed } \\
\text { For patients who do not respond to POES's, introduce ICI or MUSE or } \\
\text { VED }\end{array}$ & $\begin{array}{l}\text { - Depending on response to POESI, consider continued use of effective } \\
\text { PDESI or ICl or MUSE or VED }\end{array}$ \\
\hline & \multicolumn{2}{|c|}{ Psychosodial focas: Redefining sex life \& building an success } \\
\hline \multirow[t]{2}{*}{$\begin{array}{l}18 \text { months post } \\
\text { treatment }\end{array}$} & $\begin{array}{l}\text { Recthallenge with PDESi as needed } \\
\text { For patients who do not respond to POESi's, introduce ICl or MUSE or } \\
\text { VED }\end{array}$ & $\begin{array}{l}\text { Depending on response to POESi, cansider continued use of effective } \\
\text { PDESE or ICI or MUSE or VED }\end{array}$ \\
\hline & \multicolumn{2}{|c|}{ Pyychosacial focus: confirming goals and expectations } \\
\hline \multirow[t]{2}{*}{$\begin{array}{l}24 \text { months post } \\
\text { treatment }\end{array}$} & $\begin{array}{l}\text { - Rechallenge with PDESi as needed } \\
\text { For patients who do not respond to PDESi's, introduce ICI or MUSE or } \\
\text { VED }\end{array}$ & $\begin{array}{l}\text { Depending on response to POEST, cansider continued use of effective } \\
\text { PDESI or ICl or MUSE or VED }\end{array}$ \\
\hline & (5) & ion and Acceptance, Satisfaction with pro-erectile therapy \\
\hline
\end{tabular}


Table 3. Timelines and benchmarks post-surgery. ED: erectile dysfunction.

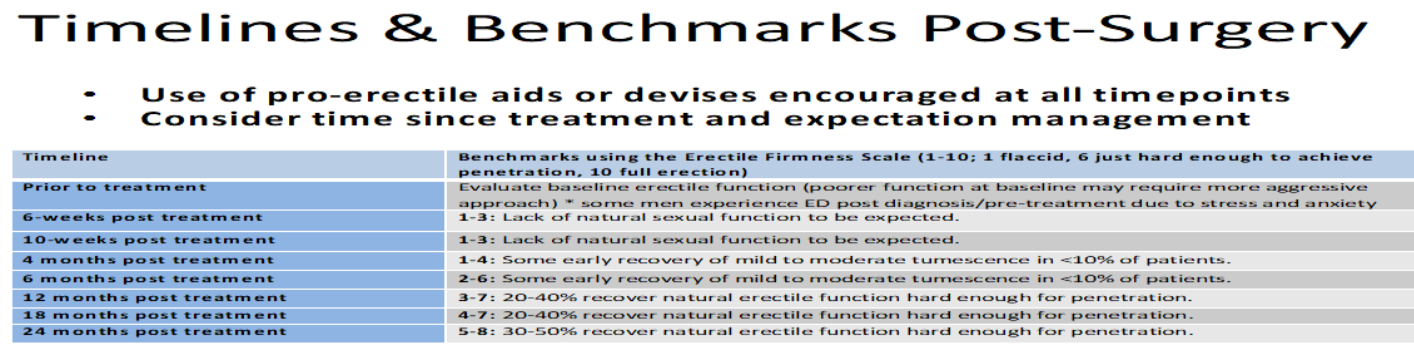

